\author{
Marquette University \\ e-Publications@Marquette
}

College of Communication Faculty Research and Publications

6-2014

\title{
Congruency and Engagement Test in an Event Marketing Sponsorship Context
}

James Pokrywczynski

Marquette University, james.pokro@marquette.edu

David L. Brinker

Marquette University

Follow this and additional works at: https://epublications.marquette.edu/comm_fac

Part of the Communication Commons

\section{Recommended Citation}

Pokrywczynski, James and Brinker, David L., "Congruency and Engagement Test in an Event Marketing Sponsorship Context" (2014). College of Communication Faculty Research and Publications. 253.

https://epublications.marquette.edu/comm_fac/253 


\title{
Congruency and Engagement Test in an Event Marketing Sponsorship Context
}

\author{
James Pokrywczynski \\ Marquette University \\ Milwaukee, WI \\ David L. Brinker \\ Pennsylvania State University \\ State College, PA
}

\begin{abstract}
:
Intercept survey data collected at a medium-size Midwestern ethnic festival are used to assess how top-of-mind and aided brand recall are influenced by ethnic congruence among attendees, brand sponsors, and the event, and by the use of passive or engaging sponsor tactics. The results are contextualized by the Elaboration Likelihood Model.
\end{abstract}

Attendees who identify as Ethnically Congruent are shown to perform significantly better on the aided brand recall instrument. Engaging tactics are shown to produce higher brand recall than passive tactics, as well as more favorable evaluations and higher purchase intent.

Keywords: Event Marketing, Event Sponsorship, Congruence, Elaboration Likelihood Model. 
NOT THE PUBLISHED VERSION; this is the author's final, peer-reviewed manuscript. The published version may be accessed by following the link in the citation at the bottom of the page.

\section{Introduction}

Event marketing is an increasingly important component in integrated marketing communications. (Sneath, Finney \& Close, 2005). Almost $\$ 26$ billion is spent annually in the U.S. (Castillo, 2010). Event marketing fits perfectly with the push for customer relationship management, which compared to other CRM activities like social media and guerilla marketing provides a personal, one-on-one opportunity between a product or sponsor and customers. The goals of event marketing include building brand awareness, enhancing brand attitudes, and in some instances making sales. This study focuses on cognitive (top-of mind, aided brand recall) and attitudinal outcomes of different event sponsorship strategies.

Sponsorship has been studied in a variety of contexts but little research has investigated ethnic festivals, at least in the U.S. Ethnic festivals provide a unique environment for sponsor activity because of the passion attendees bring to the event (Thoroski \& Greenhill, 2001; Formica \& Uysal, 1998; Simeon \& Bounincontri, 2011; Shani, Rivera \& Hara, 2009). Ethnic festival goers have strong motivations to attend because of their desire to learn more about cultural heritage, including the unique cuisine and music of that ethnic group. They are drawn to the "authenticity" and "uniqueness" of cultural events (Thoroski \& Greenhill, 2001). Cultural events are increasingly used to draw tourists and strengthen the local identity of a city or area (Simeon \& Buonincontri, 2011). A case study of four neighborhood street festivals in Toronto, Canada revealed the role that urban ethnic festivals have in generating neighborhood identity, cultural authenticity and neighborhood differentiation (McClinchey, 2008).

Sponsorships in that hotbed of motivation are likely to be well received. Only a context like NASCAR auto racing has consistently delivered the type of passionate fans that are supportive and loyal to sponsors because they understand the importance of its role in their sport (Spinda, Earnheardt \& Hugenberg, 2009). Ethnic event attendees expect this environment as well. Most ethnic festivals have "villages" with tents displaying ethnic artifacts and memorabilia sideby-side with sponsors' products and services. These sites encourage consumers to visit, ask questions, sample product, take brochures, and leave contact information for future follow-up. Because music, 
entertainment, and food are already available to attract consumers, sponsors do not need to create peripheral opportunities in order to leverage the event affiliation, unlike events surrounding NFL Kickoff, Super Bowl week, and NASCAR races.

Sponsorship has moved beyond slapping a name on an event and hoping for the best. Brands are now seeking to carry on the conversation with consumers before, during and after the event to address audiences that might otherwise be beyond their reach (Barnett, 2011). This trend is visible in the growing sponsorship executions surrounding Formula 1 motor racing, NFL football and other sports. Events are becoming brands in themselves and rights-holders place more restrictions on the use of their assets. Among the strictest of these rights-holders is the International Olympic Committee (IOC). Visa, one of the IOC's worldwide partners, launched an Olympicthemed campaign a full 18 months before the London games (Barnett, 2011).

An abundance of research has commented on the impact of event marketing sponsorship (Sneath, Finney \& Close, 2005; Chien, Cornwell \& Pappu, 2011; Florek \& Insch, 2011). This study is interested in the impact of different tactics employed by sponsors at events to engage consumers and bring attention to their brand. This festival provided an opportunity to assess two different levels of consumer engagement with a brand. Low engagement tactics typically involved simply providing marketing collateral in a booth branded with a banner bearing sponsor's logo, sometimes accompanied by representatives available to answer questions. Higher engagement tactics involved participatory opportunities, such as inviting attendees inside the booth for one-on-one experiences with the sponsor's product.

Without evidence of the impact of tactics on brand awareness (top-of- mind), brand attitudes, and behaviors, sponsors are hard pressed to evaluate outcomes of an ethnic festival sponsorship strategy. Results that show meaningful differences in the impact for these different tactics will give sponsors the guidance to make effective tactical decisions in an ethnic marketing situation. 


\section{Theory and Literature}

\section{Congruence}

Much of the sponsorship literature is concerned with conceptualizing and testing congruence between brands, sponsorship properties, and audience attributes. Congruence theories address the logic and consequences of pairing particular brands and sponsorship properties. Studies have employed congruence, or its kindred concepts "fit" and "match-up," as a central framework in a broad variety of ways; for example, Florek and Insch (2011) evaluate congruence between events and their host locales (i.e. destinations), Lee and Cho (2009) evaluate congruence between the "personalities" of sponsor brands and sporting events, and Dardis (2009) studies congruence as narrative, offering insight into how communication and messaging strategies alter perceived sponsor-property congruence. Chien, Cornwell and Pappu (2011) study models of fit across properties, arguing that a coherent sponsorship portfolio lends itself to consistent branding because audiences can understand a brand vis-à-vis its association properties that share common attributes (e.g. charity, rebelliousness, athleticism, cultural advancement).

Woisetscläger, Eiting, Haselhoff and Michaelis (2010) identify determinants of perceived brand fit. The study found a strong relationship between perceptions of fit, and two factors: "regional identification" of sponsors and perceptions that the sponsored event or organization benefits from the sponsorship relationship. Further, the study found a strong relationship between perception of sponsorship fit and "brand attractiveness" and likeability. In an ethnic festival context, many sponsors are local or regional, and they are seen as important to the survival of these non-profit festival organizations.

The practical implication of congruence is that the effectiveness of a sponsorship (either in terms of sales or brand attitudes) hinges on how an audience cognitively processes the relationships between sponsor, property, and the consumer. NASCAR auto racing is a good example of this relationship, where fans seek out sponsors hours before races to experience products, ask questions and collect samples and promotional products (King, 2011). In sports, these people are referred to as "avid fans." Cultural festivals enjoy this avid 
participation as well, in part from those who identify with the festival's heritage. Ethnic congruency for this study was defined as those respondents who self-reported their ethnicity matched that of the festival's focus.

Congruence is underpinned by affect transfer theory, which describes how audiences associate positive attitudes toward an event or organization with its sponsors (Pracejus, 2004), and image transfer theory, which suggests that audiences will relate percieved attributes of a properties to its sponsor, and vice-versa (Gwinner \& Eaton, 1999; Pracejus, 2004). Thus we expect that ethnic congruence between the event and sponsors will serve as one factor behind consumers' interest in and recollection of sponsor brands. Further, we expect that congruence between the festival's ethnic identity and the respondent's will lead to better recollection of sponsors. Formica and Uysal (1998) found two distinct groups at an ethnic festival in Italy, Enthusiasts and Moderates, but did not measure the ethnic background of these groups.

\section{Engagement}

Events, particularly of ethnic significance, represent a concentrated audience that arrives expecting to engage with the event in a more participatory sense than, for example, spectators at a sporting event. At an ethnic festival, visitors can learn craft skills, dance moves, experience music demonstrations and lessons, and of course, enjoy ethnic food and drink. This higher level of engagement resembles the central route of Petty and Cacioppo's (1986) Elaboration Likelihood Model (ELM). According to the ELM, motivation to engage a message is an important factor in whether audiences dedicate significant cognitive attention to a communication. ELM refers to this action as involvement; this study will use the term engagement to mean the same thing, emphasizing the role the message sponsor plays in trying to induce consumers to get involved with their brand at the event.

While mass media advertisers must constantly innovate and compete to retain this higher attentiveness, sponsors of festivals can expect attendees to arrive seeking direct personal engagement at the event. Brands sponsoring these events expect this engagement to 
translate into improved brand or product attitude and awareness (Barnett, 2011). The present study elaborates on this idea by examining two things: first, the tactic used by sponsors at events to more actively engage the consumer; and second, the degree to which ethnic brands are able to more readily benefit from this natural engagement from visitors. Brands with less of a match to the ethnic component of a festival still should stand to benefit, albeit to a lesser extent, from generating positive outcomes from engaged consumers (Wood, 2009). Although distinct from ethnic festivals, community events, which draw consumers who are emotionally invested and engaged in the community, have been found to be effective environments for sponsors (Close, Finney, Lacey and Sneath, 2006). Figure 1 demonstrates how the ELM model is applied to ethnic event marketing. A highly involving tactic is likely to trigger central cues like enhanced brand recall and even top-of-mind brand awareness, a goal of most marketers. A less involving tactic is likely to trigger only peripheral cues like brand recognition or aided recall. The corresponding attitudes, which are not tested in this study, will likely be distinguished by length of time brand image/attitudes last and impact on purchase intent.

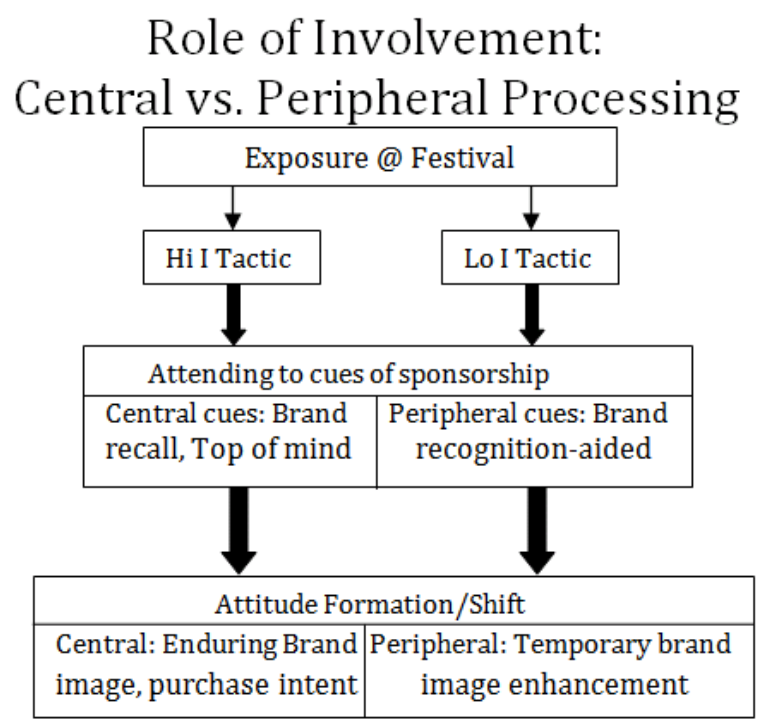

Figure 1: Application of the Elaboration Likelihood Model to ethnic festival marketing processing. 
NOT THE PUBLISHED VERSION; this is the author's final, peer-reviewed manuscript. The published version may be accessed by following the link in the citation at the bottom of the page.

Also contributing to event marketing outcomes is the respondents' self-reported preferences for particular marketing techniques. Kinney and McDaniel (1996) study the effect of different marketing executions on "attitude toward the ad" and "attitude toward the brand." While Kinney and McDaniel found ambush marketing damages brand perceptions in some situations, the study found that ambush marketing unexpectedly succeeded in a case where a tactic "created strong visual contextual cues between the event and the brand" (p. 258). The present study aims to differentiate among various techniques based on consumer preferences to identify which tactics improve the likelihood of favorable cognitive outcomes.

\section{Research Questions}

The above literature on congruence and engagement drives the following inquiries regarding sponsorship tactics in an ethnic festival environment.

RQ1) How will products with greater congruence with the event (ethnic products) resonate with festival visitors, and what role, if any, will ethnic congruence (EC) of visitors with the event have in enhancing the recall (top-on-mind and aided) of such products?

RQ2) How will a sponsor's tactics, comparing low to highly engaging individual tactics, affect recall (top-of-mind and aided)?

\section{Method}

A medium-size ethnic festival in the Midwest was the site for an intercept survey of attendees. Sponsors and their planned tactics were identified in advance with help from event organizers. A printed questionnaire with about 20 questions asked respondents about their interest in the festival, attitudes on 5-point Likert scales (alpha $=.82$ ) toward six different tactics identified from past literature as typically used by event sponsors (signage, ads on program/ticket, samples, product demonstrations, contests/sweepstakes, promotional product giveaways), likelihood to buy products from event sponsors, recall of sponsors (both top-of mind awareness for four product categories: airlines, auto dealership, allergy medicine and ethnic food product) and aided recall of event sponsors) and some demographics. The top- 
of-mind questions appeared on a separate page before the aided recall question to avoid cross fertilization of answers. The aided recall question listed about 20 sponsors, six of which were legitimate sponsors of the festival. Following standard industry practices for measuring aided recall, the 13 other choices included brands representing each of the sponsored product categories to provide feasible incorrect options. Respondents were asked to pick out the official sponsors.

The questionnaire took about 5 minutes to complete. Interviewers were instructed to stay away from the entrance gate in recruiting participants, and screened participants for having been on the festival grounds at least 30 minutes. This allowed respondents time to be exposed and experience at least some of the sponsorship activities. Total time on grounds before being surveyed was not measured, but surveying was completed each day within the first few hours of opening, leaving a limited range of exposure times to sponsorships. Respondents were most likely to cooperate when seated at picnic tables resting, eating or in between breaks in the music or performances.

\section{Results}

Of 789 survey respondents, 53\% were female. Ages ranged from 21 to over 60 , with $37 \%$ between 35 and 49 . About $45 \%$ had household incomes in the $\$ 35,000-\$ 75,000$ range. These demographics reflected prior attendance makeup for this festival. Most were motivated to attend for either the food or the music. Comparisons between ethnically congruent and non-congruent respondents showed no differences on the demographics measured (gender, age, income).

Several sponsors were local brands (car dealership, a beer), only a few sponsors had been sponsors in the past, and two sponsors were manufacturers of ethnic food items that were congruent with the festival's focus, although these items were not sold at the festival (sold at local grocers). Over half (53\%) of respondents reported ethnic congruence (ECs) with the festival. 
This $53 \%$ was compared to the others on recall of sponsor brands in two ways. First, number of sponsors recalled was compared for the two groups. Second, percentages of ECs versus non-ECS recalling specific official sponsors were compared. For top-of-mind awareness, both groups recalled an average of 1.5 sponsors. ECs consistently comprised more of those who mentioned the official sponsor for each of the four product categories, however none were statistically different (See Table 1 ). Ethnic congruence was a substantial predictor of recall of the ethnic food brand ("Mrs. T's") and the local auto dealer; experienced approximately $60 \%$ of respondents who correctly identified the official sponsor top of mind were EC, while around $40 \%$ were non-EC. Overall, the ethnic food brand was recalled by $79 \%$ of those who answered, compared to $46 \%$ or less for the other brand sponsors, demonstrating the strength of a brand ethnically congruent with the event. Despite the large disparity between groups for those recalling the airline sponsor (Sun Country), less than 50 respondents recalled the airline, making these percentages less stable. It had the toughest competition for attention; a prominent local airline was mentioned top of mind by $36 \%$ of those who answered $(n=225)$.

Table 1 Top of Mind Recall: Festival Sponsors

\begin{tabular}{|c|c|c|c|}
\hline \multirow{2}{*}{ Sponsor Brand } & & Ethnic Congruence (EC) & \multirow{2}{*}{$\begin{array}{c}\text { Non-Ethnic Congruence } \\
\text { Attendees }\end{array}$} \\
\hline & $\underline{\mathrm{n}}$ & $\underline{\text { Attendees }}$ & \\
\hline Sun Country & 29 & $62 \%$ & $38 \%$ \\
\hline Local Auto Dealer & 82 & $60 \%$ & $40 \%$ \\
\hline Allegra & 153 & $51 \%$ & $49 \%$ \\
\hline Mrs. T's & 125 & $58 \%$ & $42 \%$ \\
\hline \multicolumn{2}{|c|}{$\begin{array}{l}\text { Mean Number of Brands } \\
\text { Recalled }^{+}\end{array}$} & Avg. $=1.49$ & Avg. $=1.5$ \\
\hline
\end{tabular}

+Of participants recalling any brand

In the aided recall measure of the official sponsors, ECs consistently correctly identified a significantly larger number ( $\mathrm{F}=4.1$ $(1,579), p=.04)$ of official sponsors included in the questionnaire (See Table 2). Regarding recall of specific sponsors, the luster wore off for congruent ethnic products compared to non-congruent products when aided recall is the metric. Two ethnic food products were recalled by more ECs (57\% and 55\% respectively) but non-ethnic products also enjoyed strong recall among ECs, with a 59-41\% advantage for the airline and a local auto dealer, a 55-45\% advantage for the allergy 
NOT THE PUBLISHED VERSION; this is the author's final, peer-reviewed manuscript. The published version may be accessed by following the link in the citation at the bottom of the page.

medicine and a $52-48 \%$ recall advantage for an auto parts dealer. Significance tests for these relationships were inconclusive.

Table 2 Aided Recall: Festival Sponsors Correctly Identified in

\begin{tabular}{lccc}
\hline & & Ethnic Congruence (EC) & Non-Ethnic Congruence \\
Sponsor Brand & n Overall & Attendees & Attendees \\
Sun Country & 204 & $59 \%^{*}$ & $41 \%$ \\
Local Auto Dealer & 73 & $59 \%$ & $41 \%$ \\
Allegra & 208 & $55 \%$ & $45 \%$ \\
Mrs. T's & 258 & $55 \%$ & $45 \%$ \\
Advanced Auto Parts $_{\text {Uncle Phil's Mustard }}^{++}$ & 216 & $52 \%$ & $48 \%$ \\
Mean Number of Brands $_{\text {Recalled }}^{+}$ & 184 & $57 \%$ & $43 \%$ \\
\hline
\end{tabular}

+Of participants recalling any brand ${ }^{++}$Ethnically congruent products $* p<.05$

Both cognitive measures show a decided advantage among ECs for sponsors, regardless of the ethnic congruency of the products to the event. So Research Question 1 finds strong support for ethnically congruent (EC) visitors, and little support for ethnically congruent product sponsors.

Tactical engagement was assessed by comparing the recall (topof-mind and aided) for two sponsors, one with a low level of engagement with visitors at the sponsor site and one with a high level of engagement on-site. In the low level condition (airline), the sponsor laid out brochures on a table and had representatives available to answer travel questions if visitors posed them. In the high-level condition (allergy medicine), sponsor representatives invited visitors inside a waist-high barrier, seated them on director's style chairs to conduct a health inventory, then discussed that inventory and how the product might help.

Results showed a decided advantage in both top-of-mind and aided recall for the highly engaging allergy medicine sponsor (See Table 3). An advantage 10 times greater in top-of-mind recall for the highly engaging sponsor tactic is coupled with an almost two times greater advantage in aided recall. Both brands faced a single, highly recognized competitor in the marketplace. So, except for different product categories, the biggest distinction between the two brands was the tactic employed at the festival. Research Question 2's focus on 
NOT THE PUBLISHED VERSION; this is the author's final, peer-reviewed manuscript. The published version may be accessed by following the link in the citation at the bottom of the page.

sponsorship tactics resulted in support for the link between tactic and sponsorship impact.

Table 3 Low-Engaging vs. High-Engaging Sponsorship Tactic and Corresponding Recall

\begin{tabular}{lc}
\hline Sponsor Brand & \% Overall Sample Recall \\
\cline { 2 - 2 } Lo: Sun Country-Top of mind & $4.7 \%$ \\
Lo: Sun Country-Aided & $28 \%$ \\
Hi: Allegra-Top of mind & $46 \%$ \\
Hi: Allegra-Aided & $43 \%$ \\
\hline
\end{tabular}

Finally, consumers' attitudes toward a variety of event sponsorship tactics showed a preference for receiving something free: samples or other items (See Table 4). Festival goers had significantly (statistically) less preference for print advertisements/signs, or contests/sweepstakes offers. These preferences emerged both in ratings of each tactic as well as identification of the single tactic most likely and least likely to influence product purchase. However, all ratings were above the midpoint on the scale, suggesting consumers have a tolerance level for all sponsors' tactics. This tolerance is also reflected in an overall evaluation of likelihood to purchase sponsors' products, with a mean of 3.48 on a 5 -point scale.

Table 4 Attendees' ratings of event marketing tactics

\begin{tabular}{lc}
\hline Sponsorship Tactic & Mean Rating \\
\cline { 2 - 2 } Samples & $4.01 \mathrm{a}$ \\
Item giveaways & $3.84 \mathrm{~b}$ \\
Product demos/displays & $3.66 \mathrm{c}$ \\
Signs/banners & $3.65 \mathrm{c}$ \\
Contests/sweepstakes & $3.63 \mathrm{C}$ \\
Ads on program/ticket & $3.48 \mathrm{~d}$ \\
\hline Tactic rating means that do not share letters are significantly different at $p=.05$ using \\
Scheffe post-hoc test. Omnibus F-test is significant: F(1,692)=20874, $p<.0001$. \\
Ratings items measured on 5-point Likert scales; Cronbach's alpha reliability $=.82$ \\
\\
\\
\end{tabular}


NOT THE PUBLISHED VERSION; this is the author's final, peer-reviewed manuscript. The published version may be accessed by following the link in the citation at the bottom of the page.

\section{Conclusion/Discussion}

Over 700 ethnic festival goers provided insights that showed event sponsorship tactics can make an impact, but that some tactics and participant features make those sponsorships work even better. Level of engagement was one attribute of a sponsorship tactic assessed here and was found to generate superior cognitive impact among those exposed. Also identified was the importance of congruence between attendees and the event, especially ethnic festivals where ethnically congruent demonstrated superior brand recall. This finding adds another consumer demographic that is important for brands to consider when deciding on a sponsorship. Ethnic festival attendees seem to exhibit involvement levels similar to "avid" sports fans, a group countless industry research has identified as consumers most loyal to sponsors (King, 2011).

Congruence appears to play an important role in the top of mind recall of sponsors' brands, although less so for aided recall. Congruence between visitors and the event appear to enhance the impact that sponsors are likely to experience from their event marketing efforts. Accurate identification of event sponsors in the 4050 percent range among ethnically congruent attendees exceeds the results that major sponsors of national sports leagues only rarely, if ever, achieve (Broughton, 2011). For example, a recent national survey of hockey fans found recall of official NHL sponsors produced correct recall in only 20-30 percent of respondents across several product categories (Broughton, 2011).

Congruence between products and events was less clear in explaining the impact on brand sponsorship. One of two ethnically congruent products assessed at this event, an ethnic food product, generated the highest (aided) recall totals for any brand at the event. This didn't hold true for unaided recall, suggesting product congruence may help recognition but not recall. Testing more product categories may make this conclusion clearer in the future, as marketers seek out more congruent sponsorships. For example, the antihistamine brand Claritinhas used past sponsorship in Major League Baseball to take advantage of the congruence of "baseball played outdoors, on grass, during peak allergy season." (George, 2000) 
In addition to congruence, the survey results suggest a relationship between a brand's marketing tactic and successful brand recall. A distinction is visible between the cognitive outcomes of passive and interactive tactics. Passive brand tactics tended to produce poor brand recall, while interactive brands enjoyed more successful recall. Indeed Allegra's success is a good example of a successful highinteraction tactic engaging consumers without the benefit of ethnic congruence. This study provides empirical evidence that increased engagement between festival goers and a brand, which involves spending more time exposed to the brand, has positive benefits in the form of increased brand recall. The application of these results to the ELM model in an ethnic event marketing context adds to the understanding of how such tactics work (Petty and Cacioppo, 1986). More engaging tactics present more opportunities for consumers to centrally process information, leading to brand name registers in memory that can be more easily recalled and recalled first compared to peripherally processed brand information that results from sponsors' tactics that blend into the background of an ethnically vibrant message environment. Further research will be needed to test if the attitudinal components of the model hold up to the hypothesized outcomes posited here.

\section{Limitations and Future Research}

While the survey shows some cognitive differences between groups, conclusions about cognitive as well as attitudinal or behavioral outcomes long after participants leave the festival grounds were beyond the scope of this study. Also not available in this study were pre- sponsorship measures of recall for the brands featured at this festival. The tradeoff in studying real products in a real environment using a quasi-experimental test of tactical impact, is the sacrifice of some control. The manipulation of tactical engagement was not pretested nor were consumers asked to self-assess level of engagement with the sponsors of focus, two things future research could improve upon. However, because direct comparisons of brand recall were limited to assessing differences within the sample makeup (ethnic congruency), this becomes less of an issue.

The slightly lower percentages for aided recall compared to top of mind for congruent visitors may be function of measurement. The aided list had 20 brand choices for respondents to sift through, and its (Routledge) and permission has been granted for this version to appear in e-Publications@Marquette. Taylor \& Francis (Routledge) does not grant permission for this article to be further copied/distributed or hosted elsewhere without the express permission from Taylor \& Francis (Routledge). 
placement toward the end of the questionnaire may have resulted in greater fatigue and desire to complete the task. Also, almost all respondents answered the aided recall question, while participation ranged from 20 to 79 percent for those who answered one of the unaided top-of-mind recall questions across the selected product categories.

Future research should surely investigate the boundaries of the congruence effect. In a study on sports sponsorship, Woisetscläger et al. (2010) identifies antecedents to perceived fit, finding a strong link to perceived benefits of the sponsorship and regional identification. However, the study found weak evidence of the linkage to perceived sincerity, explaining that "one can assume that fans have learned that, in general, all sponsors pursue commercial goals." This is a potential starting point for ethnic festival research to examine, as affect or image transfer may explain how perceived authenticity of the event may attenuate this consumer skepticism.

Identity theories are another conceptual area especially applicable when it comes to understanding how ethnic festival goers or sports fans relate to the events or teams they support (Wendkos, 2011). "Fans' identities are formed through their identification with social groups and individual behavioral roles. When fans identify highly with a team-related social group, they demonstrate more loyalty to the group and immerse themselves in the group's culture" according to Wendkos. The underlying psychology behind this "fan avidity" needs to be further investigated in the context of ethnic event marketing.

\section{References}

1. Barnett, M. (2011, Jan. 6), Sponsorship: Event backers drive audience participation, Marketing Week, 25.

2. Broughton, David (2011, June 20), Verizon's recognition rate sets survey record, Sports Business Journal, 10.

3. Castillo, D. (2010, July 7), New PQ Media Report Finds U.S. Branded Entertainment Spending on Consumer Events \& Product Placement Dipped Only $1.3 \%$ to $\$ 24.63$ Billion in 2009 \& on Pace to Grow 5.3\% in 2010, Exceeding Most Advertising \& Marketing Segments, Product Placement News, www.productplacement.biz, accessed 9/13/11.

Journal of Promotion Management, Vol. 20, No. 3 (May/June 2014): pg. 345-357. DOI. This article is (C) Taylor \& Francis (Routledge) and permission has been granted for this version to appear in e-Publications@Marquette. Taylor \& Francis (Routledge) does not grant permission for this article to be further copied/distributed or hosted elsewhere without the express permission from Taylor \& Francis (Routledge). 
NOT THE PUBLISHED VERSION; this is the author's final, peer-reviewed manuscript. The published version may be accessed by following the link in the citation at the bottom of the page.

4. Chien, P.M., Cornwell, T.B. and Pappu, R. (2011), Sponsorship portfolio as a brand-image creation strategy, Journal of Business Research, 64, 142-149.

5. Close, A., Finney, R., Lacey, R., and Sneath, J. (2006). Engaging the Consumer through Event Marketing: Linking Attendees with the Sponsor, Community, and Brand. Journal of Advertising Research, 46(4), 420-433.

6. Dardis, F. (2009). Attenuating the Negative Effects of Perceived Incongruence in Sponsorship: How Message Repetition Can Enhance Evaluations of an "Incongruent" Sponsor. Journal of Promotion Management, 15, 36-56.

7. Florek, M. and Insch, A. (2011). When Fit Matters: Leveraging Destination and Event Image Congruence. Journal of Hospitality Marketing \& Management. 20(3), 265-286.

8. Formica, S. and Uysal, M. (1998). Market Segmentation of an International Cultural-historical event in Italy. Journal of Travel Research, 36, 1624.

9. George, John (2000, Nov. 6), Claritin uses MLB to target consumers, Sports Business Journal, 35.

10. Gwinner K.P. and Eaton J. (1999), Building brand image through event sponsorships: The role of image transfer, Journal of Advertising, 28(4), 47-57.

11. King, B. (2011, April 29), What makes fans crazy about sports, Sports Business Journal, 15-22.

12. Kinney, L. and McDaniel, S. (1996), Strategic Implications of AttitudeToward-the-Ad in Leveraging Event Sponsorships, Journal of Sport Management, 10, 250-261.

13. Lee, H.S. and Cho, C.H. (2009), The Matching Effect of Brand and Sporting Event Personality: Sponsorship Implications, Journal of Sport Management, 23, 41-64.

14. McClinchey, K. (2008). Urban Ethnic Festivals, Neighborhoods, and the Multiple Realities of Marketing Place. Journal of Travel and Tourism Marketing, 25, 251-264.

Journal of Promotion Management, Vol. 20, No. 3 (May/June 2014): pg. 345-357. DOI. This article is (c) Taylor \& Francis (Routledge) and permission has been granted for this version to appear in e-Publications@Marquette. Taylor \& Francis (Routledge) does not grant permission for this article to be further copied/distributed or hosted elsewhere without the express permission from Taylor \& Francis (Routledge). 
NOT THE PUBLISHED VERSION; this is the author's final, peer-reviewed manuscript. The published version may be accessed by following the link in the citation at the bottom of the page.

15. Petty, R.E. and Cacioppo, J. T. (1986). Communication and persuasion: Central and peripheral routes to attitude change. New York: Springer/Verlag.

16. Pracejus, J. W. (2004). Seven Psychological Mechanisms Through Which Sponsorship Can Influence Consumers. In L.R. Kahle \& C. Riley (Eds.), Sports Marketing and the Psychology of Marketing Communications (pp. 175-190). Mahwah, NJ: Lawrence Erlbaum.

17. Shani, A., Rivera, M. and Hara, T. (2009). Assessing the Viability of Repeat Visitors to Cultural Events: Evidence from the Zora! Festival. Journal of Convention \& Event Tourism, 10(2), 89-104.

18. Simeon, M. and Buonincontri, P. (2011). Cultural Event as a Territorial Marketing Tool: The case of the Ravello Festival on the Italian Amalfi Coast. Journal of Hospitality Marketing \& Management, 20, 385-406.

19. Sneath, J., Lacey, R., Finney, R.Z., and Close, A.G. (2005), An IMC Approach to Event Marketing: The Effects of Sponsorship and Experience on Customer Attitudes, Journal of Advertising Research, $45(4), 373-381$.

20. Spinda, J., Earnheardt, A. and Hugenberg, L. (2009), Checkered Flags and Mediated Friendships: Parasocial Interaction among NASCAR Fans, Journal of Sports Media, 4(2), 31-55.

21. Thoroski, C. and Greenhill, P. (2011). Putting a Price on Culture: Ethnic Organizations, Volunteers, and the Marketing of Multicultural Festivals. Ethnologies, 23, 189-209.

22. Wendkos, Max (2011, August 29), Teams can better reach fans by knowing what motivates them, Sports Business Journal, 13.

23. Woisetscläger, D., Eiting, A., Haselhoff, V. and Michaelis, M. (2010), Determinants and consequences of sponsorship fit: A study of fan perceptions, Journal of Sponsorship, 3(2), 169-180.

24. Wood, E. (2009), Evaluating Event Marketing: Experience or Outcome? Journal of Promotion Management, 15, 247-268.

Journal of Promotion Management, Vol. 20, No. 3 (May/June 2014): pg. 345-357. DOI. This article is (C) Taylor \& Francis (Routledge) and permission has been granted for this version to appear in e-Publications@Marquette. Taylor \& Francis (Routledge) does not grant permission for this article to be further copied/distributed or hosted elsewhere without the express permission from Taylor \& Francis (Routledge). 